\title{
Modification of a Direct Injection Diesel Engine in Improving the Ignitability and Emissions of Diesel-Ethanol-Palm Oil Methyl Ester Blends ${ }^{\dagger}$
}

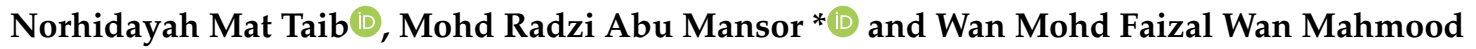 \\ Department of Mechanical Engineering, Faculty of Engineering and Built Environment, Universiti Kebangsaan \\ Malaysia, UKM Bangi 43600, Selangor, Malaysia \\ * Correspondence: radzi@ukm.edu.my \\ † This paper is an extended and revised article presented at the International Conference on Sustainable Energy \\ and Green Technology 2018 (SEGT) on 11-14 December 2018 in Kuala Lumpur, Malaysia.
}

Received: 13 May 2019; Accepted: 6 July 2019; Published: 10 July 2019

\begin{abstract}
Blending diesel with biofuels, such as ethanol and palm oil methyl ester (PME), enhances the fuel properties and produces improved engine performance and low emissions. However, the presence of ethanol, which has a small cetane number and low heating value, reduces the fuel ignitability. This work aimed to study the effect of injection strategies, compression ratio (CR), and air intake temperature $\left(T_{i}\right)$ modification on blend ignitability, combustion characteristics, and emissions. Moreover, the best composition of diesel-ethanol-PME blends and engine modification was selected. A simulation was also conducted using Converge CFD software based on a single-cylinder direct injection compression ignition Yanmar TF90 engine parameter. Diesel-ethanol-PME blends that consist of 10\% ethanol with 40\% PME (D50E10B40), D50E25B25, and D50E40B10 were selected and conducted on different injection strategies, compression ratios, and intake temperatures. The results show that shortening the injection duration and increasing the injected mass has no significant effect on ignition. Meanwhile, advancing the injection timing improves the ignitability but with weak ignition energy. Therefore, increasing the compression ratio and ambient temperature helps ignite the non-combustible blends due to the high temperature and pressure. This modification allowed the mixture to ignite with a minimum $C R$ of 20 and $T_{i}$ of $350 \mathrm{~K}$. Thus, blending high ethanol contents in a diesel engine can be applied by advancing the injection, increasing the $C R$, and increasing the ambient temperature. From the emission comparison, the most suitable mixtures that can be operated in the engine without modification is D50E25B25, and the most appropriate modification on the engine is by increasing the ambient temperature at $350 \mathrm{~K}$.
\end{abstract}

Keywords: combustion characteristics; injection strategies; compression ratio; intake temperature

\section{Introduction}

Palm oil methyl ester (PME) produced from edible sources, such as palm oil, is known as the best biodiesel in Malaysia [1]. PME has a performance that is almost similar to diesel fuel, but with good engine emissions [2]. However, the high density and viscosity of PME require much fuel consumption in the real-application engine. Therefore, blending PME in diesel was able to reduce the harmful emission from the diesel and improve the engine performance due to its high cetane number. However, the high density and viscosity of PME need the ethanol presence to prevent the injection system problem in the engine and reduce the fuel consumption. The reason is that ethanol has the lowest viscosity amongst diesel and PME, as explained in Table 1 . Besides, ethanol is another renewable energy fuel, promising good engine emissions. Along with the energy efficient vehicle (EEV) concept, 
the PME and ethanol presence can reduce the emissions, improve the engine performance, and reduce petroleum dependency.

Table 1. Thermophysical properties of diesel, ethanol, and palm oil methyl ester (PME) [3-6].

\begin{tabular}{cccc}
\hline Properties & Diesel & Ethanol & PME \\
\hline Molecular formula & $\mathrm{NC}_{7} \mathrm{H}_{16}$ & $\mathrm{C}_{2} \mathrm{H}_{5} \mathrm{OH}$ & $\mathrm{C}_{18} \mathrm{H}_{34} \mathrm{O}_{2}$ \\
Viscosity (cSt) & 3.49 & 1.5 & 4.8 \\
Density (kg/m3) & 834 & 788 & 881 \\
Low heating value & 43.2 & 27 & 37.8 \\
(MJ/kg) & 50 & 8 & 56 \\
Cetane number & 25 & 107 & - \\
Octane number & 0.0 & 34.8 & 11 \\
Oxygen contents (\%) & 483 & 638 & 469 \\
Auto-ignition & & & \\
temperature (K) & & &
\end{tabular}

Ethanol was recommended to be used in commercial diesel engines due to its low production cost for biofuels. Ethanol is a low viscous liquid that is able to reach good air-fuel mixture homogeneity. However, ethanol that contains a deficient cetane number reduced the engine performance and delayed the combustion [7]. The poor ethanol ignitability is probably due to its higher evaporation enthalpy compared with diesel. Thus, the temperature was reduced during combustion due to the withdrawn heat during combustion [8]. The long delay in combustion causes the fuel to be less combustible and forms the excess fuel in the engine. However, a perfectly blended composition should be identified to have excellent fuel combustion.

Meanwhile, high ethanol contents in blends also affect the ignitability of the fuel blends, and the excess fuel leads to fuel deposition inside the cylinder. Therefore, modification of the injection parameter was suggested to improve the ignitability of blends. Modifications of injection parameters include the injection mass, injection pressure, injection duration, and injection timing. Modification of the injection timing can improve engine performance. However, not all the applied injection strategies can solve the ignitability problem of diesel-ethanol-PME blends.

Few researchers have studied the effect of advancing the injection timing for high oxygenated alternative fuels, such as ethanol and PME. The studies found that advancing the injection timing increased the in-cylinder pressure and heat release rate (HRR). However, advancing the injection timing can increase $\mathrm{NO}_{x}$ emission [9]. The reason is that advancing the injection timing allows the fuel to mix early and increase the temperature. Thus, the $\mathrm{NO}_{x}$ reaction takes part during the combustion easily.

Meanwhile, the presence of ethanol and PME also is another reason for the $\mathrm{NO}_{x}$ formation due to the high oxygen contents in both fuel molecules [10]. Therefore, suitable blends of diesel, ethanol, and PME should be formed to reduce the $\mathrm{NO}_{x}$ formation. Another study was conducted in improving the ethanol ignitability by increasing the engine compression ratio. Increasing the compression ratio of the engine increases the pressure and temperature to enhance the fuel ignitability and engine efficiency [11]. Considering that the auto-ignition temperature for the blends was high, another approach, such as increasing the ambient temperature at the intake, also helped improve the ignitability [12]. A study from Kuszewski (2018) shows that improving the ambient gas improved the auto-ignition of diesel-ethanol blends. The results showed that the ignition delay for a high ethanol percentage is longer than that for diesel. The maximum percentage of ethanol use in this experiment is $14 \%$ [13].

This research works aimed to study the ignitability of diesel-ethanol-PME blends and optimize the best solution in solving the non-combustible fuel blends. The non-combustible fuel blends are recognized when no ignition occurs, which usually happened on the high ethanol content blends when operating at high engine speeds. The simulation was conducted using Converge CFD software based on the direct injection Yanmar TF90 diesel engine parameter. The simulation was performed 
for low, medium, and high ethanol contents, containing 10\% ethanol and 40\% PME in 50\% diesel (D50E10B40), D50E25B25, and D50E40B10 blends at 900 RPM, 1600 RPM, and 2400 RPM. The first work was to identify the non-combustible blends. The injection parameter, compression ratio, and intake temperature were modified due to the ignitability problem of high ethanol contents in the blends. The optimization of the best solution was identified from the combustion characteristic progress to solve the ignitability problem faced by high ethanol content blends.

\section{Methodology}

In this study, blends were simulated to analyze their ignitability and emission. Grid independence and emission tests were also conducted to determine the blend composition. The emission results from the simulation are verified with the results obtained from experimental work.

\subsection{Simulation of Blends Ignitability and Emission}

In this study, simulation work was conducted to analyze the combustion characteristics and emissions of diesel-ethanol-PME. The combustion characteristics analysis was used to study the combustion behavior of the fuel when entering the combustion chamber. This process includes the ignition delay, thermal efficiency, in-cylinder pressure and temperature, and heat release during combustion. This work focused on the ignitability optimization of high ethanol presence in diesel-PME blends. The simulation was conducted based on the single cylinder direct injection compression ignition Yanmar TF90 engine parameter by using Converge CFD software.

Converge CFD software is a unique software equipped with adaptive mesh refinery (AMR) with the ability to refine the mesh automatically during the combustion. A grid independence test was conducted to identify the most suitable grid size for meshing. This test aims to eliminate any unnecessary grid meshing sizes to improve simulation outcomes. The grid independence test was performed on different grid sizes of $0.003 \mathrm{~m}, 0.004 \mathrm{~m}, 0.005 \mathrm{~m}$, and $0.006 \mathrm{~m}$. The diesel fuel results were verified with the experiment results obtained by Ibrahim (2015) [14]. The most suitable grid applied on the engine model is $0.004 \mathrm{~m}$ by activating the AMR function to allow small automatic meshing occurring during the injection and combustion.

In this software, an engine model was prepared based on the engine specification, as shown in Figure 1. The three boundaries, which consist of a piston, head, and liner of the cylinder, were assigned as the initial conditions of each boundary. The cylinder wall (liner) and head were set in a fixed position with the wall temperature of $363 \mathrm{~K}$ and $319 \mathrm{~K}$. Meanwhile, the piston was set as a moving boundary with the wall temperature of $403 \mathrm{~K}$ [15]. The parameter of the engine and injection system based on the real engine parameter for the Yanmar TF90 direct injection diesel engine was also explained in Table 2.

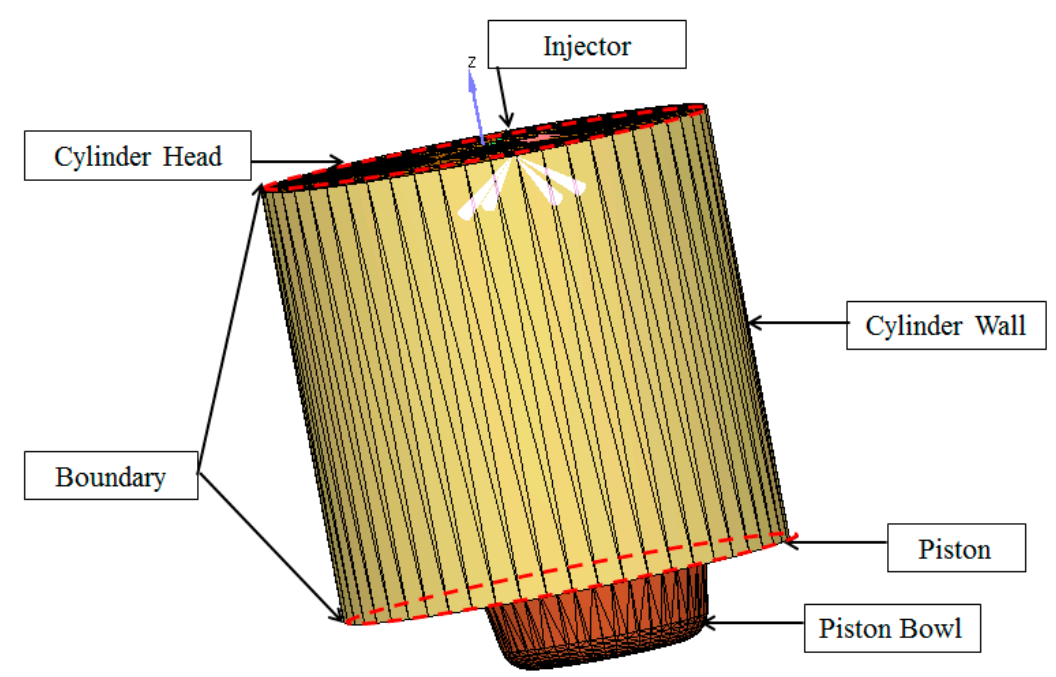

Figure 1. Yanmar TF90 combustion cylinder model. 
Table 2. Engine and injection system specification [15].

\begin{tabular}{cccc}
\hline \multicolumn{2}{c}{ Engine Specification } & \multicolumn{2}{c}{ Injection System Specification } \\
\hline Engine model & Yanmar TF90 & Number of nozzles & 4 \\
Bore $(\mathrm{m}) \times$ stroke $(\mathrm{m})$ & $0.085 \times 0.087$ & Nozzle diameter $(\mathrm{mm})$ & 0.22 \\
Connecting rod length $(\mathrm{m})$ & 0.13 & Injection pressure $(\mathrm{MPa})$ & 19.613 \\
Piston bowl diameter $(\mathrm{m})$ & 0.0463 & Injection duration $\left({ }^{\circ} \mathrm{CA}\right)$ & 16 \\
Piston bowl depth $(\mathrm{m})$ & 0.016 & Injection timing $\left({ }^{\circ} \mathrm{CA}\right.$ BTDC) & -18 \\
Compression ratio & 18 & Cone angle $\left(^{\circ}\right)$ & 10 \\
\hline
\end{tabular}

The Yanmar TF90 engine is a natural aspirated air single cylinder engine with a direct injection system. The air is entered the combustion chamber at the atmospheric pressure and temperature before the piston compressed it. The simulation is conducted for a cycle starting right after the intake valve closes at $-168^{\circ} \mathrm{CA}$ BTDC until the exhaust valve opens at $138^{\circ} \mathrm{CA}$ ATDC. The initial temperature and pressure of all the boundaries were set at the atmospheric pressure and temperature, which is $101 \mathrm{kPa}$ and $300 \mathrm{~K}$. The real injection timing of this engine was started at $-18^{\circ} \mathrm{CA}$ BTDC located at the center of the cylinder head. The combustion was simulated using a SAGE combustion model in a closed-system chamber. The mathematical correlation was solved with the text data. In this simulation, the chemical reaction, gas transport, and thermodynamic data for all the fuel blends were obtained from the Lawrence Livermore National Laboratory. Meanwhile, the chemical kinetic reaction of biodiesel underwent a mechanism reduction process to reduce the number of reactions in the data. The emission model used in this simulation was the Zeldovich $\mathrm{NO}_{x}$ model, which utilizes the Hiroyasu soot model to identify emissions from combustion.

\subsection{Blend Composition}

A few different diesel-ethanol-PME blend compositions were applied to the engine running at 900 RPM, 1600 RPM, and 2400 RPM. The blends were injected through the injector nozzle into the engine combustion chamber. From all the blends, three blends were selected to run at 1600 RPM and 2400 RPM. The blends are D50E10B40 (50\% diesel, 10\% ethanol, and 40\% PME), D50E25B25, and D50E40B10. Table 3 presents the mass fraction of these blends. These blends were chosen to study the effect of ethanol and the PME presence in the engine through combustion analysis.

Table 3. Blend composition. D50E10B40: 50\% diesel, 10\% ethanol, and 40\% PME, etc.

\begin{tabular}{ccccc}
\hline \multirow{2}{*}{ No } & \multirow{2}{*}{ Blends } & \multicolumn{3}{c}{ Mass Fraction } \\
\cline { 3 - 5 } & & Diesel & Ethanol & PME \\
\hline 1 & Diesel & 1.0 & 0.0 & 0.0 \\
2 & D50E10B40 & 0.5 & 0.1 & 0.4 \\
3 & D50E10B0 & 0.83 & 0.27 & 0.0 \\
4 & D50E25B25 & 0.5 & 0.25 & 0.25 \\
5 & D50E0B25 & 0.67 & 0.0 & 0.33 \\
6 & D50E40B10 & 0.5 & 0.4 & 0.1 \\
7 & D50E0B10 & 0.83 & 0.0 & 0.27 \\
\hline
\end{tabular}

As explained in Table 3, another diesel-ethanol blend named as D50E10B0 was operated and compared with the D50E10B40 blend to study the effect of PME presence in diesel-ethanol blends. Meanwhile, two diesel-PME blends such as D50E0B25 and D50E0B10 were compared with D50E25B25 and D50E40B10 to study the effect of ethanol in these two diesel-ethanol-PME blends. However, due to the presence of ethanol, which has a very low cetane number, the non-combustible blends were identified from the combustion analysis at each engine speed.

From the analysis, the non-combustible blends are then selected for a few modifications to improve its ignitability. The modifications, such as the injection system parameter, engine compression ratio, 
and air intake temperature, were selected. These modifications were conducted to find the most suitable modification that can be applied to improve the ignitability of the fuels. The simulation was performed at two engine speeds: namely, 1600 RPM and 2400 RPM. Table 4 shows the modification applied to the engine by comparing the combustion characteristics from the in-cylinder pressure and HRR during combustion. From the results, the ignitability of each blend is investigated by identifying its ignition delay. Ignition delay is defined as the duration between the start of fuel injection and the start of ignition. Ignition results from the rapid rise in pressure and the occurrence of HRR. In addition, the purposes of blending the ethanol and PME in diesel are to reduce the greenhouse emission. Therefore, carbon footprint and $\mathrm{NO}_{x}$ emission analysis were also conducted from the simulation to identify the emission efficiency of each fuel blend and its modification.

Table 4. Injection system and engine modification parameter.

\begin{tabular}{|c|c|c|c|c|}
\hline \multicolumn{3}{|c|}{ Injection Modification } & \multirow{2}{*}{$\begin{array}{c}\text { Compression Ratio } \\
\text { Modification }\end{array}$} & \multirow{2}{*}{$\begin{array}{c}\text { Ambient } \\
\text { Temperature, } T_{i}\end{array}$} \\
\hline Injection Timing & Injection Duration & Injected Mass & & \\
\hline$-25^{\circ} \mathrm{CA}$ BTDC & $10^{\circ} \mathrm{CA}$ & $25 \mathrm{mg}$ & $\underline{18}$ & $300 \mathrm{~K}$ \\
\hline$-18^{\circ} \mathrm{CA}$ BTDC & $\overline{16^{\circ} \mathrm{CA}}$ & $19 \mathrm{mg}$ & $\overline{20}$ & $\overline{350 \mathrm{~K}}$ \\
\hline$\overline{-10^{\circ} \mathrm{CA} \text { BTDC }}$ & - & $\overline{16 \mathrm{mg}}$ & 24 & $400 \mathrm{~K}$ \\
\hline$-8^{\circ} \mathrm{CA}$ BTDC & - & $8 \mathrm{mg}$ & - & - \\
\hline
\end{tabular}

\subsection{Validation of Emissions from Blend Combustion through Experiments}

The simulation for the D50E10B40 and D50E25B25 blends was experimentally validated on the YanmarTf90 Engine. Table 2 presents the specifications. Without any further modifications, the engine ran at 900 RPM, 1600 RPM, and 2400 RPM at a 2-kW load. Figure 2 shows a schematic of the experiment setup. The emission of the diesel-ethanol-PME blend combustion was measured using a KANE gas analyzer, which assessed the $\mathrm{CO}, \mathrm{CO}_{2}$, and $\mathrm{NO}_{x}$ emissions. The limitation in this experiment is that the combustion characteristics could not be measured for validation. Therefore, the emission results from the experiment were compared with the simulation results. 


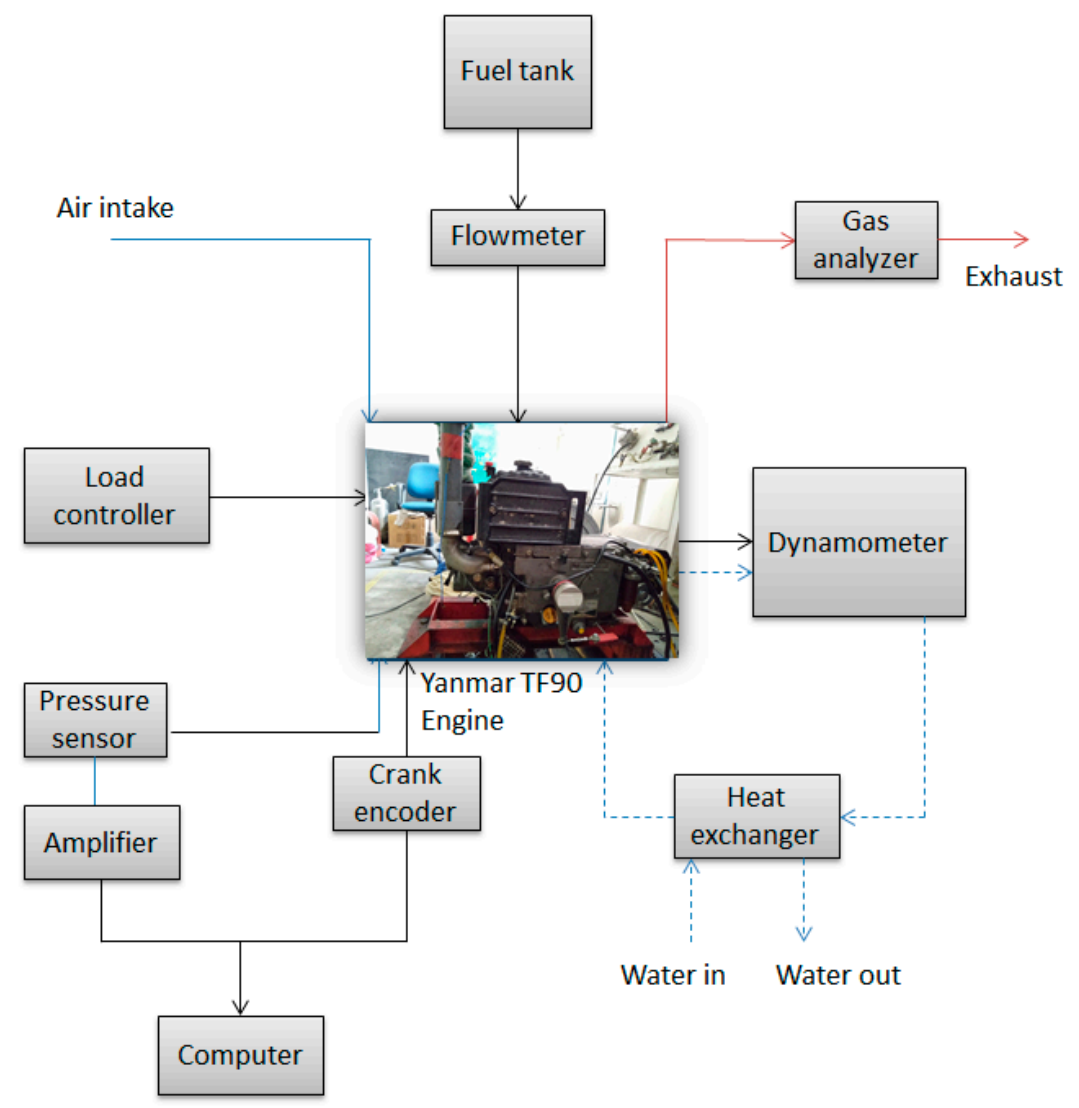

Figure 2. Schematic of the experimental engine setup.

\section{Results and Discussion}

The results of this study are focused on the ignitability of diesel-ethanol-PME blends at various compositions and engine speeds. The ignition abilities of the blends are discussed briefly for different cases especially when the blends contained high ethanol percentage. Thus, another method was applied to improve the ignition ability by working on the injection parameter change, compression ratio, and ambient temperature improvement.

\subsection{Grid Independence Test}

A grid independence test was conducted to identify the optimum grid size for meshing. The results of combustion characteristics were compared with the experiment results to determine the best grid size for meshing. Figure 3 shows the in-cylinder pressure of diesel fuel from a simulation with different grid sizes compared with the experiment results when the engine is running at 1600 RPM. The grid size comparison shows that $0.004 \mathrm{~m}$ is the most suitable grid size for meshing, which obtains the minimum error value compared with the experiment results at the peak pressure. The comparison of data sizes and operation working durations are also part of the primary consideration. Table 5 shows the comparison of data sizes, simulation durations, and error percentages obtained from the pressure results. A grid size of $0.004 \mathrm{~m}$ is the most suitable grid for further simulations. 

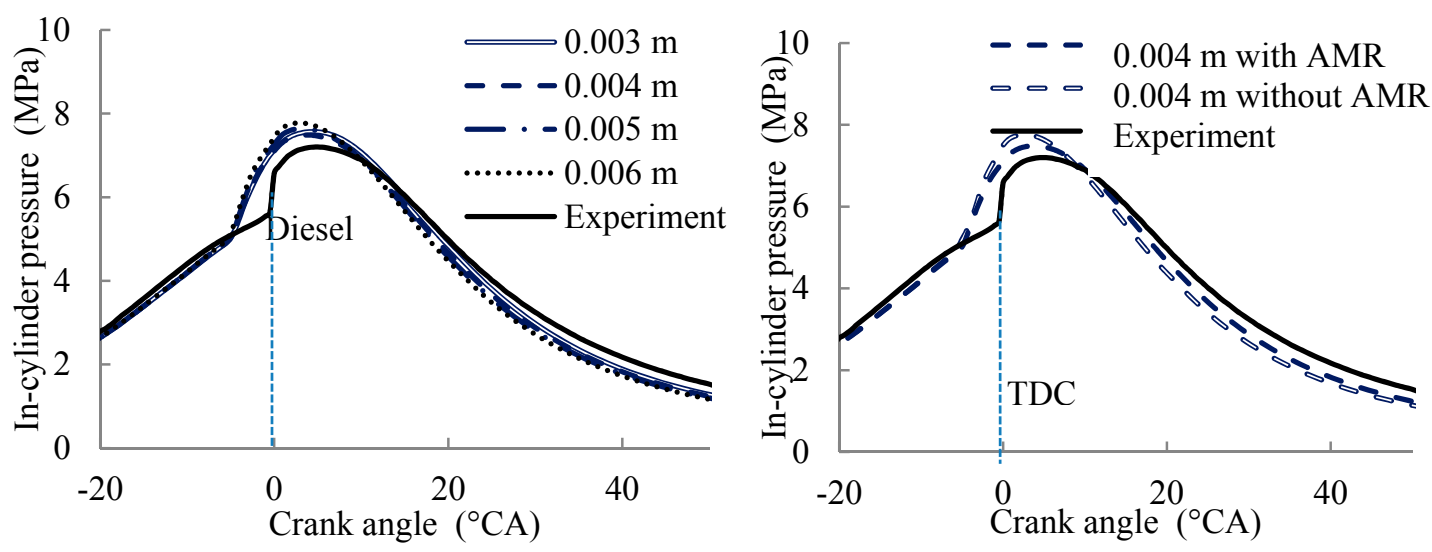

Figure 3. Pressure of diesel fuel from the simulation with different grid sizes and with and without adaptive mesh refinery (AMR) function when the engine is running at 1600 RPM compared with the experiment.

Table 5. Comparison of data sizes, simulation durations, and error percentages from the pressure during combustion with different grid sizes.

\begin{tabular}{cccccc}
\hline \multirow{2}{*}{ Grid Size } & \multicolumn{2}{c}{ Error Percentage (\%) } & Number of & $\begin{array}{c}\text { File Size } \\
\text { (GB) }\end{array}$ & $\begin{array}{c}\text { Duration } \\
\text { (min) }\end{array}$ \\
\cline { 2 - 3 } & At TDC & Peak Pressure & & & \\
\hline 0.003 & 8.424 & 5.120 & 1441390 & 14.0 & 1557 \\
0.004 & 8.190 & 4.024 & 614589 & 7.76 & 996 \\
0.004 without AMR & 14.318 & 7.817 & 614874 & 6.14 & 439 \\
0.005 & 10.848 & 6.145 & 504128 & 4.87 & 664 \\
0.006 & 13.244 & 8.022 & 500624 & 4.32 & 454 \\
\hline
\end{tabular}

\subsection{Ignitability and Emission of Diesel-ethanol-PME Blends with High Ethanol Contents}

Figure 4 shows the comparison of in-cylinder pressure and HRR between the D50E10B40, D50E25B25, and D50E40B10 blends running at high engine speeds of 1600 RPM and 2400 RPM. The graph shows that the operating engine at high engine speed influenced the fuel ignitability. The result shows that at high engine speed, the ignitability of the blends weakened due to the ethanol presence that has low heating value and low cetane number. The reason is that the cetane number of ethanol was approximately five to 10 times lower than that of diesel and PME [16]. The low heating value of the fuel also indicates that the blends release a very low heat during the compression. This condition leads to a lack of energy and delays the ignition.

Figure 5 shows the ignition delay of the blends influenced by ethanol contents. The results show that the ignition condition is worsened when the high ethanol contents were used. Ignition delay timing in the crank angle at high engine speed is relatively lengthened, and shows opposite results in an ignition delay time in milliseconds due to the fast engine piston motion. When the engine speed moved rapidly, the engine duration to complete a cycle was shortened. This condition results in insufficient air into the cylinder and reduces the pressure in the cylinder. As presented in the graph, the D50E25B25 blend was not able to ignite when running at 2400 RPM. Meanwhile, the ignitability potential of the D50E40B10 blend was worsened at all speeds except for at 900 RPM. 


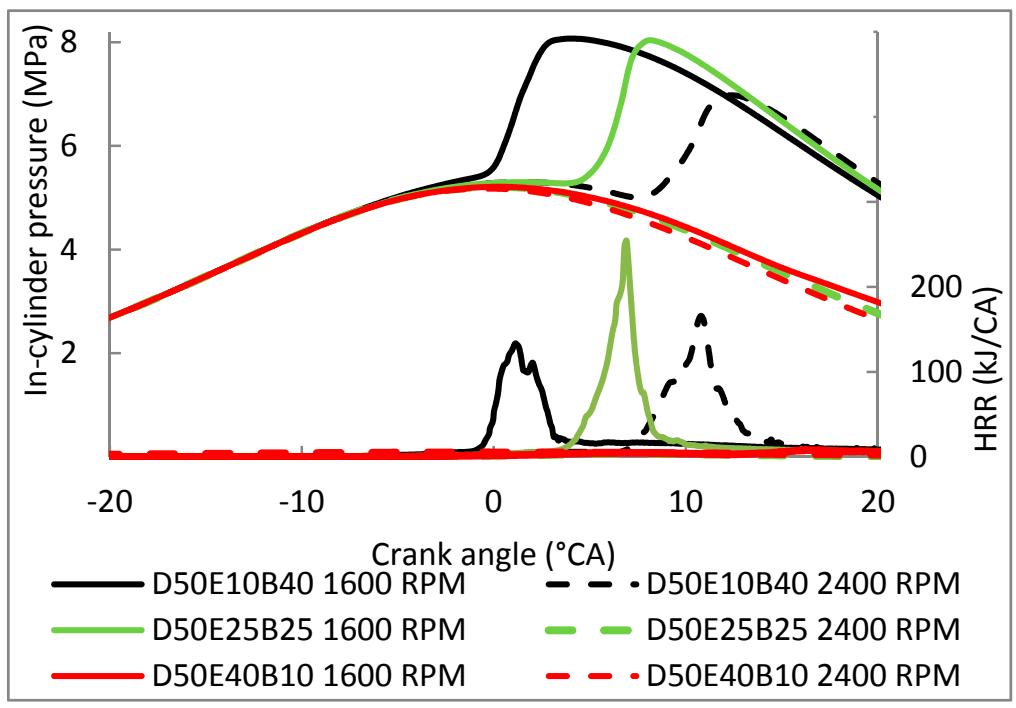

Figure 4. Graph of in-cylinder pressure and heat release rate (HRR) of D50E10B40, D50E25B25, and D50E40B10 blends at 1600 RPM and 2400 RPM.

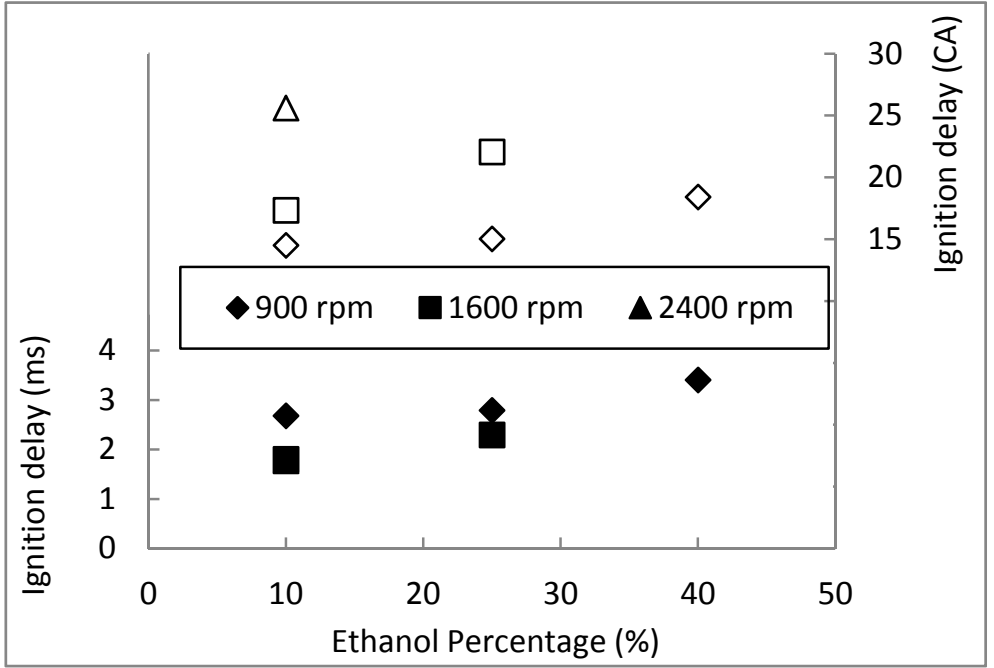

Figure 5. Ignition delay of the combustible blends with different ethanol percentages.

Figure 6 shows the three-dimensional (3D) visual temperature distribution for D50E10B30, D50E25B25, and D50E40B10 blends at 1600 RPM running at normal Yanmar TF90 engine specification without modification. Evidently, the high ethanol percentage in blends cannot be ignited at this engine specification due to the low ambient temperature. The maximum temperature for the blends without ignition is $850 \mathrm{~K}$. This temperature is not high enough to ignite the blends with high ethanol contents. Therefore, the ignitability of ethanol present in the fuel decreases at high engine speed. However, the high ethanol contents in blends have low ignition potential and have small peak pressure due to the delay. In addition, it also has a rapid rise in HRR and small peak pressure that will cause the ignition duration. The results show that the maximum ethanol contents in the blend composition are $25 \%$ when running at 1600 RPM and are decreased when running at a high engine speed. 


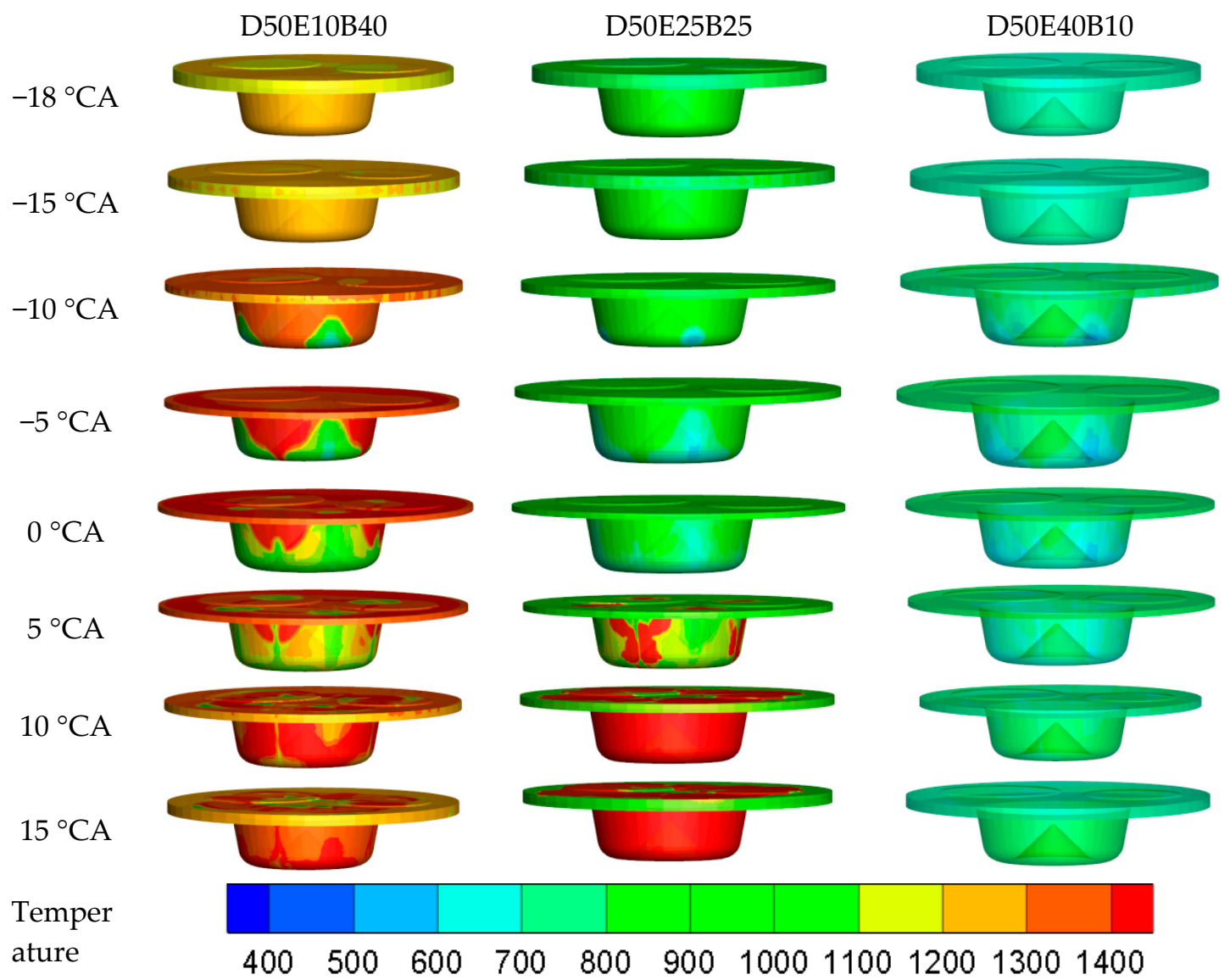

Figure 6. Three-dimensional (3D) view of ignitability difference between different diesel-ethanol-PME blends at 1600 RPM.

The emission of simulation results obtained from the combustion of all the blends is validated with the emission results from the experiment. However, due to the ignition problem faced by the D50E40B10 blend, the experiment is conducted only for D50E10B40 and D50E25B25. The average emission of $\mathrm{CO}_{2}, \mathrm{CO}$, and $\mathrm{NO}_{x}$ are calculated and compared to the experiment. Figure 7 shows the comparison of $\mathrm{CO}, \mathrm{CO}_{2}$, and $\mathrm{NO}_{x}$ emissions of D50E10B40, D50E25B25, and D50E40B10 blends.

The simulation and experiment results show that the $\mathrm{NO}_{x}$ and $\mathrm{CO}_{2}$ emissions of the D50E10B40 blend are insignificantly different. Meanwhile, the $\mathrm{NO}_{x}, \mathrm{CO}$, and $\mathrm{CO}_{2}$ emissions of D50E25B25 are unstable, especially at a high engine speed. This phenomenon is due to the high ethanol contents with unstable combustion due to insufficient oxygen. The D50E25B25 blend also showed evident separation after a certain time during the experiment, which is an indication for unstable combustion. Separation occurs due to the high water presence from ethanol. Hence, diesel is probably the only fuel that can be injected into the combustion chamber. The emission results show that the simulation accuracy of the experiment has a minimum error of $5 \%$ to $30 \%$, except for unstable combustion blends. Therefore, the simulation for the combustion characteristics and emissions of diesel-ethanol-PME blends is validated for further study. 
D50E10B40
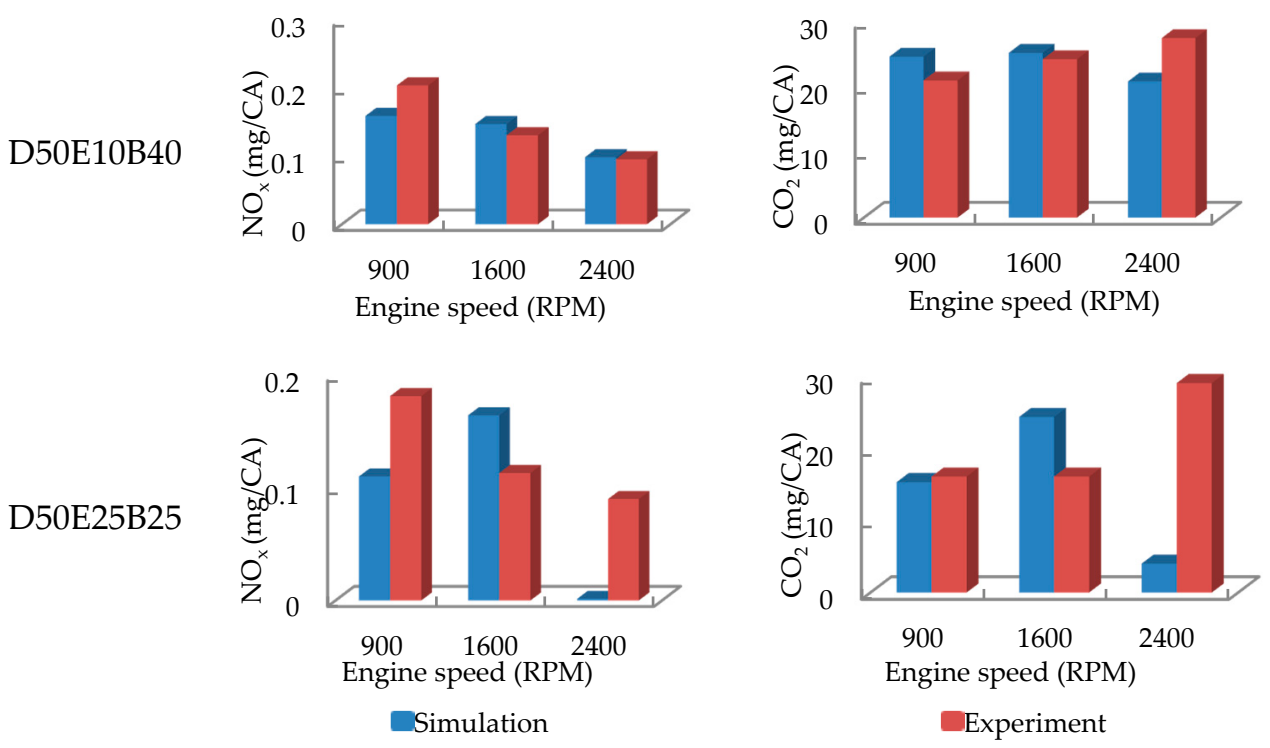

Figure 7. Comparison of emissions from simulations and experiments for D50E10B40 and D50E25B25 blends.

Figure 8 shows the graph of tri-fuel blends and dual-fuel blends to compare the difference of in-cylinder pressure and HRR when ethanol or PME is added. The results obviously show that the blend without any PME presence (D50E10B0) has slightly higher pressure and HRR compared with other blends. Meanwhile, the D50E0B10 blend that does not consist of any ethanol presence has shorter ignition delay and is obviously easily ignited compared with D50E40B10. This outcome is due to the biodiesel, which has a high cetane number and increased temperature to early ignite the fuel. D50E0B25 has a shorter ignition delay than D50E25B25. The diesel-PME blends without ethanol presence show a positive result to the ignition delay. Although the ignition delay of the blends with high PME contents is shortened, the HRR of the blends is very low. This condition is influenced by the properties of PME, which has high viscosity, a high molecular weight, and low burning velocity [16]. Therefore, the presence of ethanol in D50E25B25 helps the blends obtain high HRR for improved engine thermal efficiency.

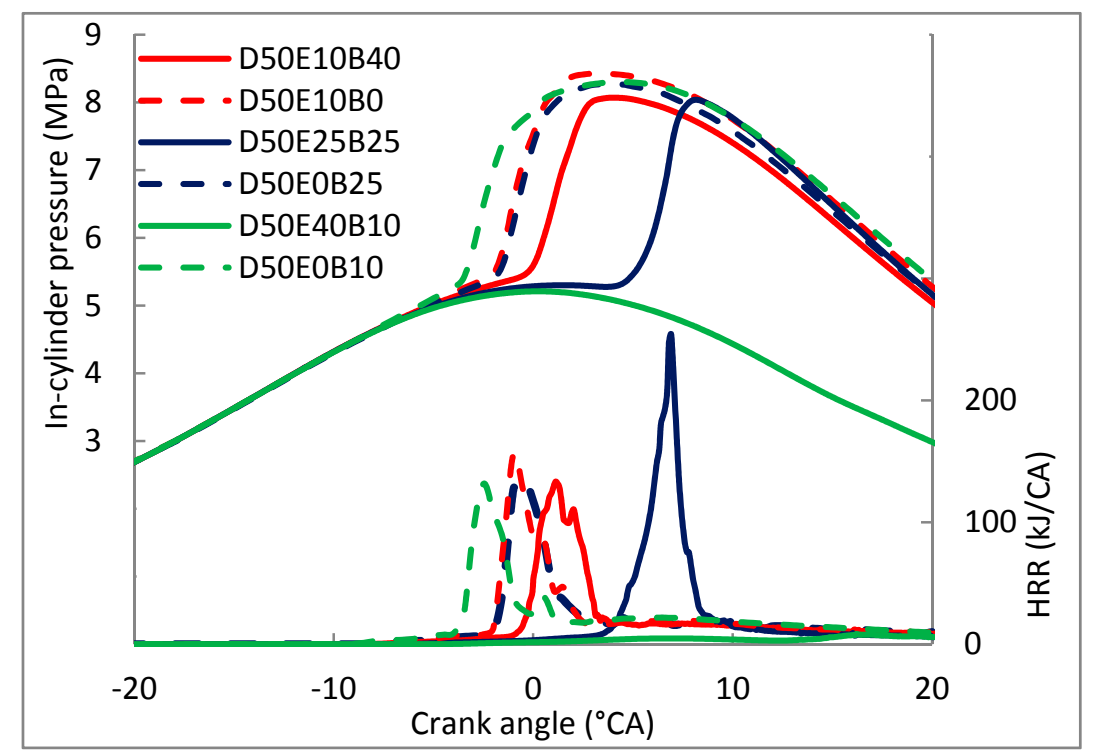

Figure 8. Pressure and HRR graphs of the blends with and without the addition of ethanol and PME. 


\subsection{Ignitability of Diesel-Ethanol-PME Blends with Injection Parameter Modification}

Injection parameters, such as injection duration, injected mass, and injection timing, were modified due to the ignition problem of the D50E25B25 blend at 2400 RPM and the D50E40B10 blend at 1600 RPM and 2400 RPM. Figure 9 shows the graph of in-cylinder pressure and HRR against the crank angle of the D50E25B25 blend by using different injection durations. Figures 10 and 11 show the graph of pressure and HRR for the D50E25B25 and D50E40B10 blends by using different injected masses and injection timings at $1600 \mathrm{RPM}$. The result shows that modification of the injection duration has no significant change on pressure and HRR. The study from Adnan et al. (2012) also compared the injection duration of diesel but with hydrogen. They found the same trend: that no significant change is observed on the pressure and HRR for different injection durations [17]. Furthermore, reducing the injected fuel mass also reduces fuel ignitability. Consuming a great amount of fuel to the engine for high ethanol blends does not give positive results. Therefore, the injection duration and fuel mass should be maintained with $16{ }^{\circ} \mathrm{CA}$ and $19 \mathrm{mg}$ of fuel, considering that increasing the fuel amount will not meet the EEV concept.

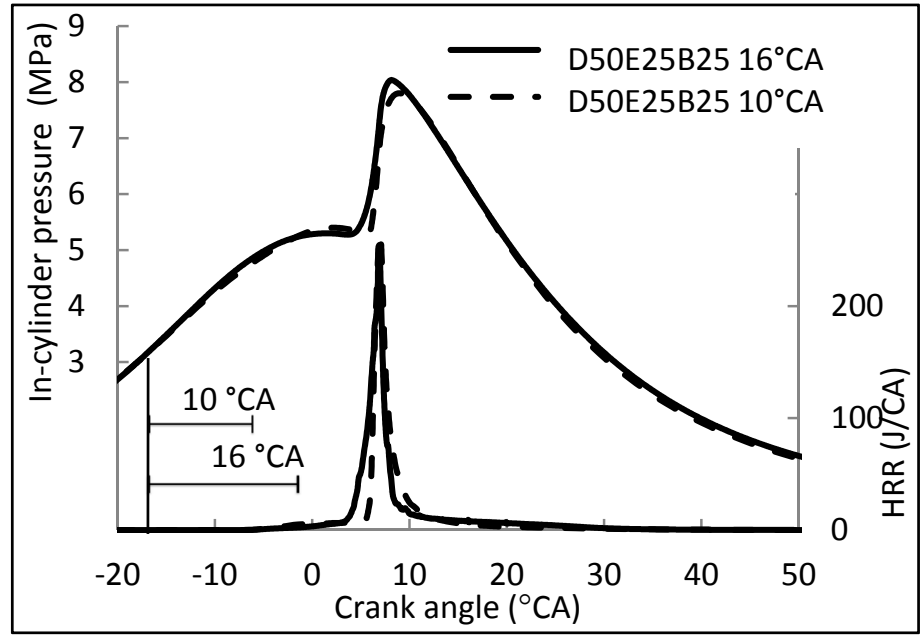

Figure 9. In-cylinder pressure and HRR graph of D50E25B25 blend against crank angle by using different injection durations.

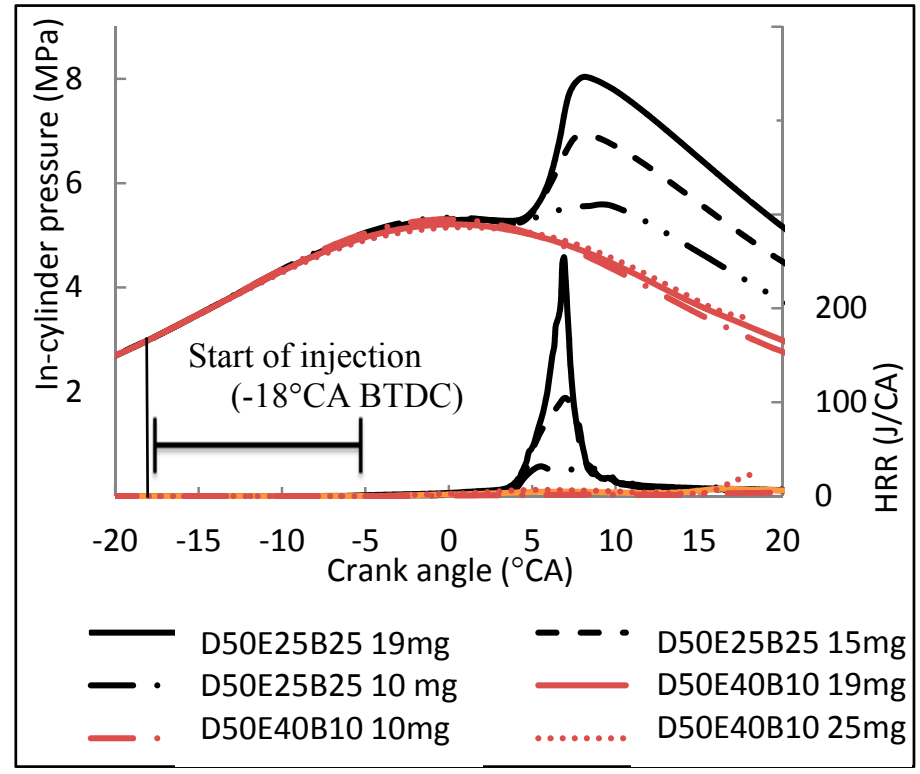

Figure 10. In-cylinder pressure and HRR graph of D50E25B25 and D50E40B10 blends against crank angle by using different injected mass. 


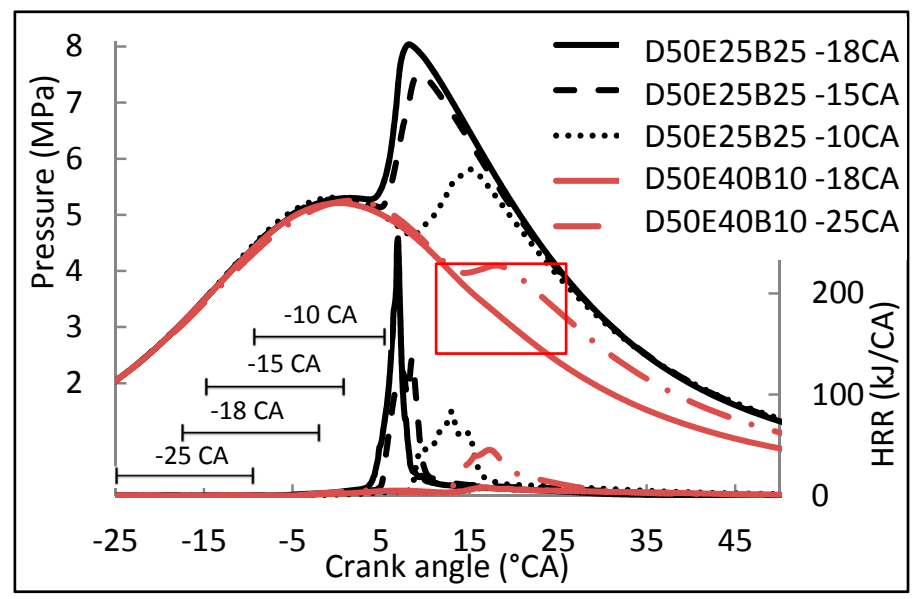

Figure 11. In-cylinder pressure and HRR graph of D50E25B25 and D50E40B10 blends against a crank angle by using different injection times.

Figure 11 illustrates the pressure and HRR graph of D50E25B25 and D50E40B10 blends running at $1600 \mathrm{RPM}$ with different injection times. The graph shows that advancing the injection time from $-18{ }^{\circ} \mathrm{CA}$ BTDC to $-25^{\circ} \mathrm{CA}$ BTDC for D50E40B10 blends exhibited positive results in solving the ignition problem. However, the ignition of this fuel is very weak, as marked in the red box in Figure 11. Meanwhile, retarding the injection timing of D50E25B25 reduced the pressure and HRR. This phenomenon proves that only advancing the injection timing can improve the blend ignitability, especially for the blends with high ethanol contents. The reason is that the advance injection can allow the fuel to be mixed early with air and increase the temperature during the premixed phase and ignite the fuel [18]. Compared with the previous study, Mendes Guedes et al. (2018) also found that an advanced injection timing increases the pressure and HRR during combustion. In addition, the advanced ignition has a short ignition duration that is able to reduce the carbon emission problems. However, high temperature may lead to $\mathrm{NO}_{x}$ emission [8].

However, advancing the injection timing at the early time before the top dead center (TDC) may lead to another problem. Although advancing the injection timing improves the fuel ignitability, injecting the fuel too early can lead to the incomplete fuel combustion. Thus, the situation will increase the hydrocarbon, carbon monoxide, and soot emission. As observed in the emission graphs in Figure 12, emissions of $\mathrm{CO}, \mathrm{HC}$, and $\mathrm{C}_{2}$ are high with the advancement of the injection timing for the D50E25B25 blend. A few studies found that advancing the injection timing reduced the carbon emissions, while considering that the ignition started early. However, the transition of liquid fuel turning into gas is very slow, especially at high engine speeds, and leads to incomplete combustion due to the ethanol presence [19]. Figure 12 shows the emission graphs for D50E40B10 blends with two different injection timings. Injection at $-18{ }^{\circ} \mathrm{CA}$ BTDC does not have any ignition due to the high ethanol presence. Advancing the injection timing with $-25^{\circ} \mathrm{CA}$ BTDC was able to ignite the fuel, as shown in Figure 8 .

As illustrated in the graph, $\mathrm{CO}_{2}, \mathrm{CO}$, and $\mathrm{NO}_{x}$ emissions still occur, because the reaction between the hydrocarbon and air occurs in the combustion chamber. However, the reaction itself is insufficiently high to release additional energy for igniting the fuel, which results in a low temperature. Therefore, the ignition hardly occurs. The graph shows that the $\mathrm{CO}, \mathrm{CO}_{2}, \mathrm{C}_{2}$, and $\mathrm{NO}_{x}$ emissions are too low for the D50E40B10 blend without modification. The hydrocarbon (HC) emission is higher than that of the other modifications, because $\mathrm{C}$ and $\mathrm{H}$ do not completely react with other elements upon injection. No $\mathrm{NO}_{x}$ emission is observed because the temperature in the cylinder is insufficiently high to trigger a reaction between nitrogen and oxygen to form $\mathrm{NO}_{x}$. 

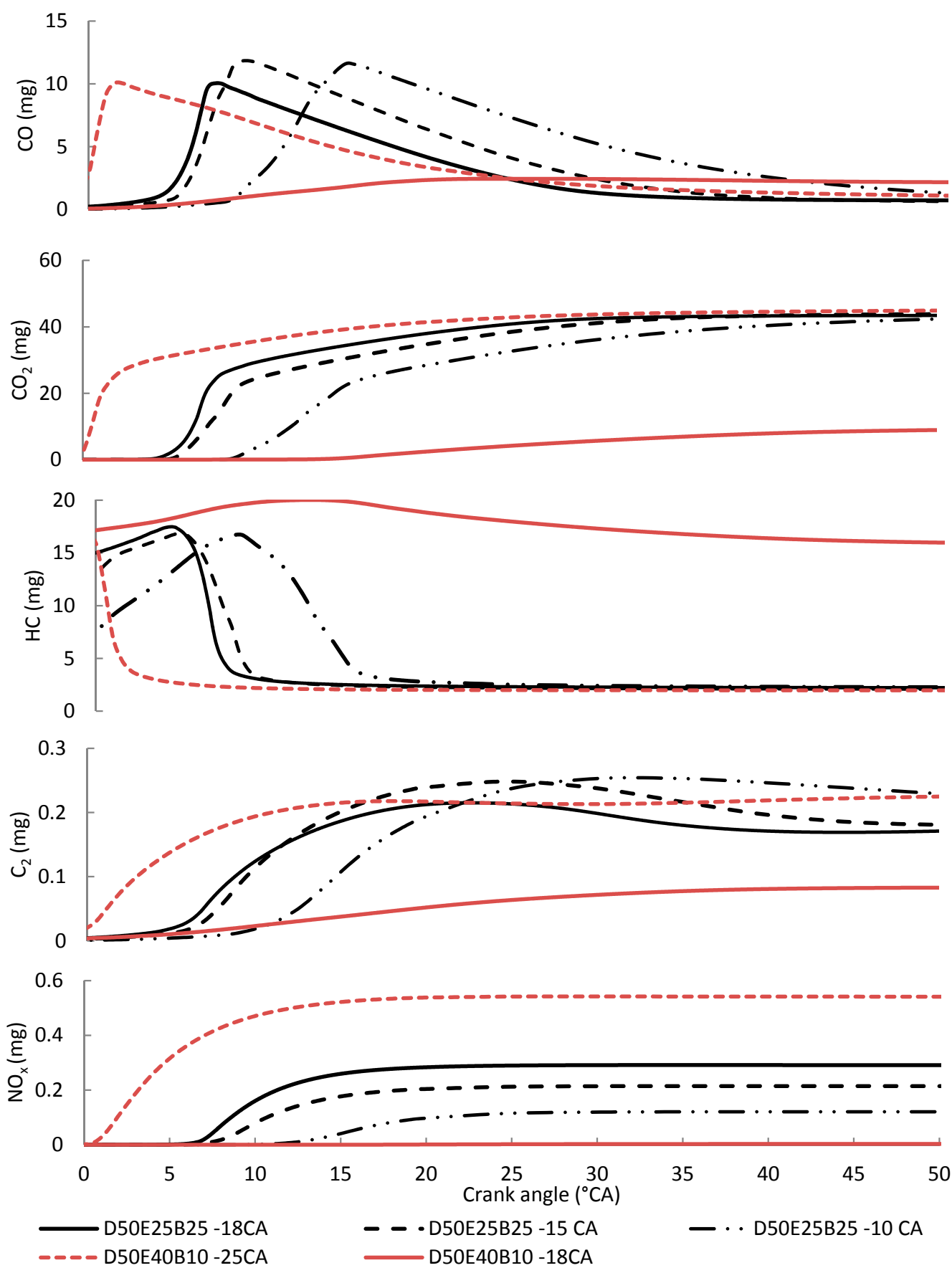

Figure 12. Emission graphs of D50E25B25 blends running by using different injection timing at 1600 RPM.

However, advancing the injection timing too early before TDC increased the emission of $\mathrm{CO}$, $\mathrm{CO}_{2}, \mathrm{C}_{2}$, and $\mathrm{NO}_{x}$. The reason is that the fuel is injected too early before the temperature in the cylinder reaches fuel auto-ignition. In addition, high ethanol blends have a very high auto-ignition temperature. Therefore, the fuel mixture in the combustion chamber is hard to ignite. This condition will lead to a long ignition delay. Therefore, the unburned fuel in the cylinder increases and leads to incomplete combustion. The trend of emissions between D50E25B25 and D50E40B10 blends is significantly different due to the ignitability of blends at a high ethanol ratio. Moreover, advancing the injection timing earlier than $-25^{\circ} \mathrm{CA}$ BTDC increases the temperature before the TDC and increases the $\mathrm{NO}_{x}$ emission. 


\subsection{Ignitability of Blends with Compression Ratio and Intake Temperature Modification}

Diesel-ethanol-PME blends with high ethanol percentage faced the ignitability problem. Due to this reason, the compression ratio and intake temperature of the engine is modified.

\subsubsection{Compression Ratio}

The D50E40B10 blend has significantly shown that the ignitability of this blend is very weak due to the low cetane number and delay of ignition. Therefore, compression ratio modification has been selected to improve the ignitability. Figure 13 shows the graph of in-cylinder pressure and HRR of D50E40B10 blends operated at two different engine speeds of 1600 RPM and 2400 RPM by using various cylinder compression ratios of 18,20 , and 24 . The standard compression ratio of 18 of the engine was not able to combust the fuel due to the low amount of air at high engine speed operation. Therefore, a modification of cylinder compression ratio was proved to be able to increase the in-cylinder pressure. Meanwhile, HRR decreases with the compression ratio, which is probably due to the decrease of specific energy caused by the low heating value of ethanol $[20,21]$. The reason is that the large cylinder volume is able to increase the temperature and pressure in the cylinder. High temperature and pressure in the cylinder help ignite the blends with high ethanol contents, considering that ethanol has a high auto-ignition temperature [19].

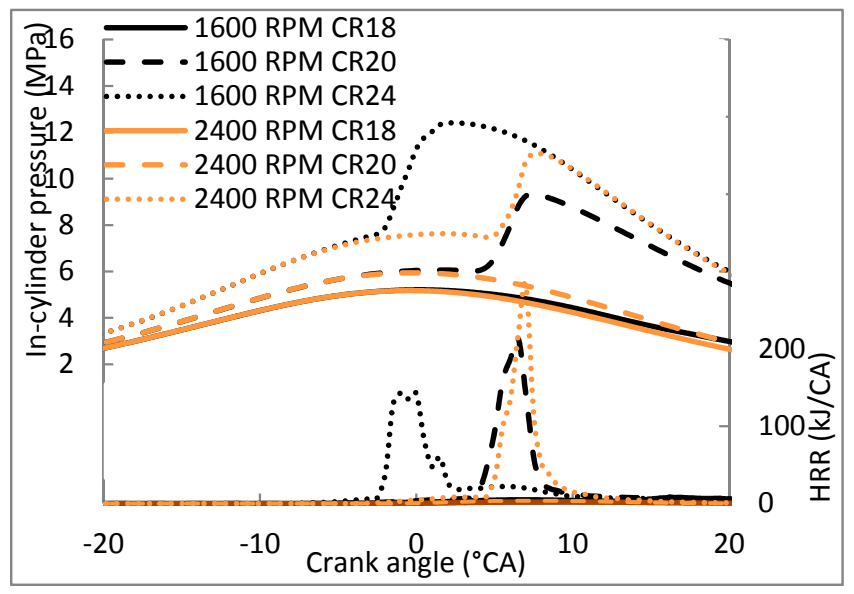

Figure 13. In-cylinder pressure and HRR graph of the D50E40B10 blend against a crank angle by using different engine compression ratios at different engine speeds.

The high engine compression ratio is also able to solve the problems of the D50E40B10 blends at high engine speed. In addition, the minimum CR allowed for the D50E40B10 blend operated at 1600 RPM is CR20, and at 2400 RPM is CR 24. A high compression ratio should be applied on high engine speed because the reaction rate is very fast and rapidly increases the pressure [11]. However, as the CR increases, the knock and misfiring phenomenon also occur, as observed on the HRR curve. Knock occurs when the unburned fuel in the cylinder is ignited by itself before the piston reached the TDC and forced the piston to go down. Therefore, increasing the compression ratio may solve the ignition problem of the blends with high ethanol contents. However, this phenomenon leads to unwanted phenomena, such as knocking and misfiring.

In addition, increasing the compression ratio can lead to another pollution problem. Figure 14 shows the emission graphs of D50E40B10 blends running at $1600 \mathrm{RPM}$ at different compression ratios. The results show that increasing the compression ratio increases the emission of $\mathrm{CO}_{2}$ and $\mathrm{NO}_{x}$ emissions and reduces the $\mathrm{CO}$ emissions during the expansion stroke. The graphs also show that the emissions of the blends running at a normal compression ratio are too low for $\mathrm{CO}, \mathrm{CO}_{2}, \mathrm{C}_{2}$, and $\mathrm{NO}_{x}$ emissions. This situation proves that the fuel ignition at this condition is too weak, and the reaction of 
hydrocarbon with air is too low. The heat release from the reaction is insufficiently high to increase the temperature for ignition.
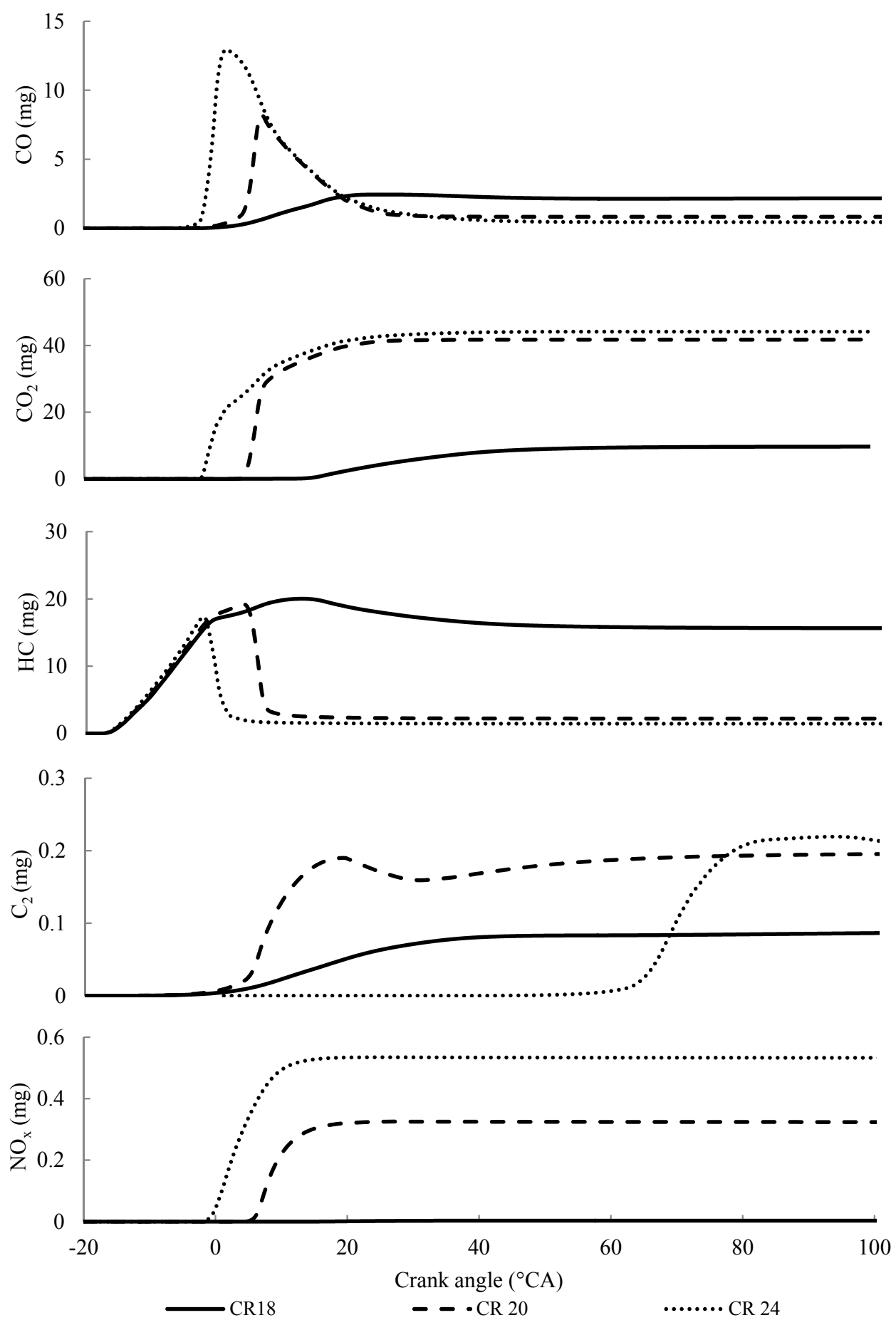

Figure 14. Emission graphs of the D50E40B10 blend at different compression ratios running at 1600 RPM.

The emission difference of CO between CR 20 and CR 24 was really significant, with a difference of approximately $55 \%$. Meanwhile, the percentage difference of $\mathrm{CO}_{2}$ emissions between $\mathrm{CR} 20$ and CR 24 was only $5 \%$. However, the emissions of hydrocarbon and soot for CR 24 was found to be lower than those for CR 20, because increasing the compression ratio shortened the ignition delay, and the temperature in the cylinder is high enough to combust the fuel and reduce the emissions of $\mathrm{HC}$ and $\mathrm{CO}$. However, high temperature in the cylinder also increases the $\mathrm{NO}_{x}$ emissions [22]. The 
previous study also found similar changes in emissions, wherein the high compression ratio reduces the emissions of carbon but increases the $\mathrm{NO}_{x}$ emission [23,24]. From the comparisons of the blends on the combustion characteristics and emissions, CR 20 is considered the best for the D50E40B10 blend at 1600 RPM, and CR 24 works well with the blend at 2400 RPM.

\subsubsection{Intake Temperature}

Another method for improving the ignitability of high ethanol content blends is by increasing the in-cylinder temperature that can be applied by increasing the temperature or air at the intake $T_{i}$. Figure 15 shows the in-cylinder pressure and HRR of D50E40B10 blends operated at 2400 RPM by applying different $T_{i}$. The results show that increasing the air temperature increases the temperature in the cylinder and is able to improve the fuel ignitability. Increased $T_{i}$ ignites the fuel early, has wide combustion, and produces a great amount of heat power. However, early ignition at high engine speed can cause misfiring. In addition, burning the diesel-ethanol-PME blends at $400 \mathrm{~K}$ has lower in-cylinder pressure compared with that at $350 \mathrm{~K}$. Studies from Akashah et al. (2015) also found that a high ambient temperature has the weakest energy and low in-cylinder pressure for ethanol combustion. This phenomenon proves that the high ethanol presence has this effect whereby it causes the in-cylinder pressure at the highest ambient temperature to decrease [25]. Meanwhile, using $350 \mathrm{~K}$ of intake temperature increases the pressure rapidly and exhibits the highest peak pressure. Therefore, $350 \mathrm{~K}$ is the most suitable intake temperature needed to ignite the D50E40B10 blend when operating at high engine speed.

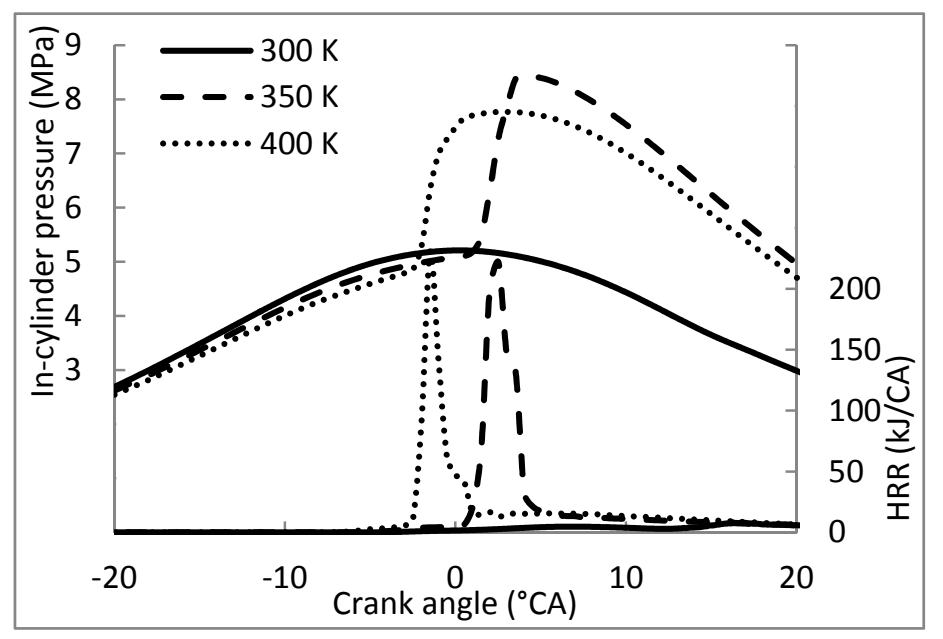

Figure 15. In-cylinder pressure and HRR graph of the D50E40B10 blend against a crank angle at 2400 RPM by using a different intake temperature, $T_{i}$.

Normally, to increase the intake temperature in the real engine, an intake heating system or exhaust gas recirculation (EGR) system can be applied to the engine with the temperature rise of approximately $350 \mathrm{~K}$ [7]. However, implementing an EGR should be reconsidered, because it can reduce engine efficiency. However, this process is very useful in reducing $\mathrm{NO}_{x}$ emissions. Therefore, applying the air-heating intake system is another solution in the future to control the temperature of air intake with the minimum temperature of $350 \mathrm{~K}$ if more than $40 \%$ ethanol in the blends is used. A patent from Linkenhoger (2005) designed an air-heating intake system to heat up the air and vaporize the fuel to improve the engine efficiency, improve the fuel economy, increase the engine power, reduce the carbon emission, and increase the engine life [26].

Figure 16 shows the emission results of the D50E40B10 blend at different intake temperatures running at $1600 \mathrm{RPM}$. The study found that increasing the intake temperature emits increased $\mathrm{CO}$ and $\mathrm{CO}_{2}$ emissions. The $\mathrm{NO}_{x}$ emissions also increased with the increase of the temperature in the cylinder 
and contributed to $\mathrm{NO}_{x}$ reactions. The soot formation was also increased with the increment of intake temperature due to the shortened ignition delay [27].
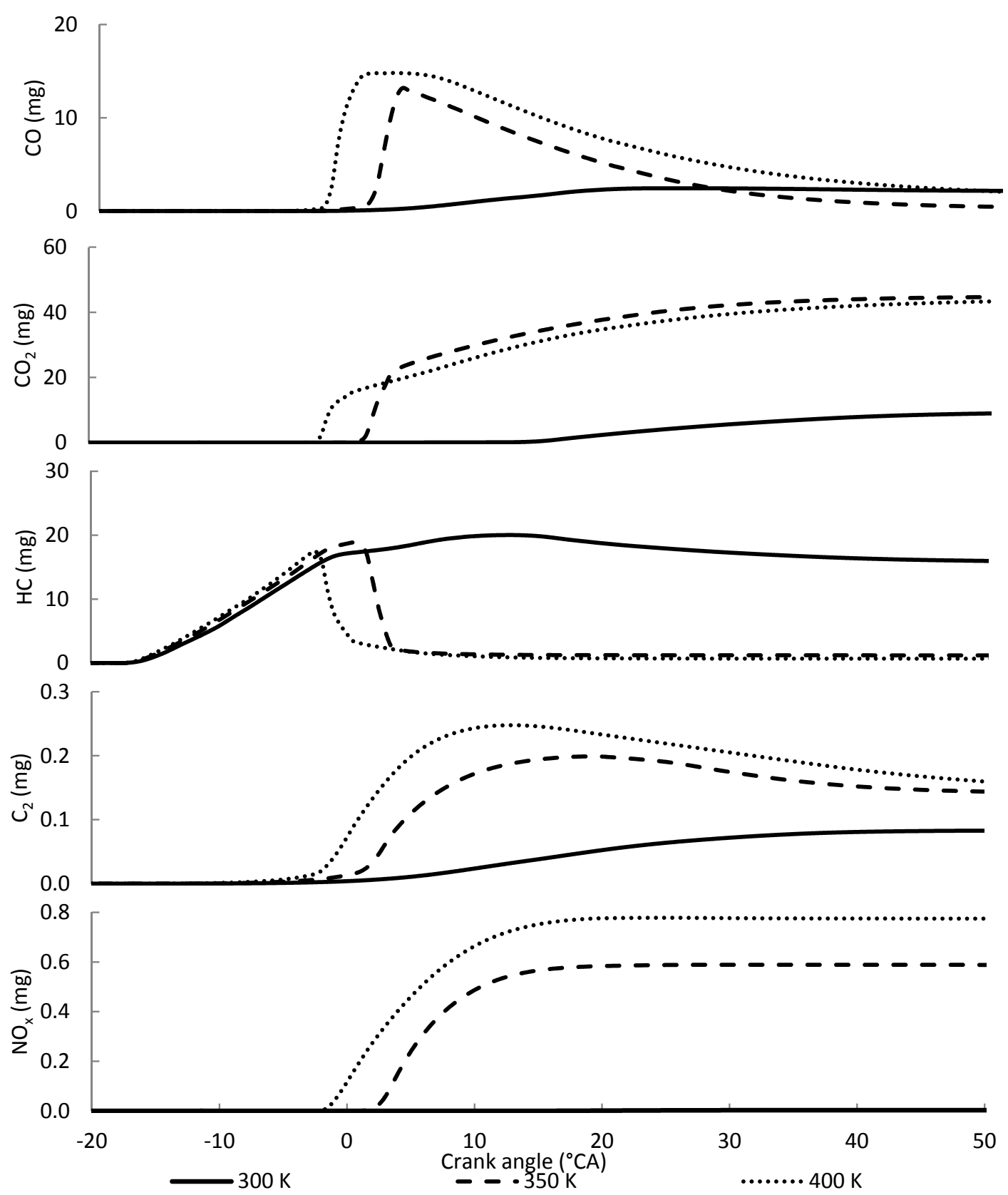

Figure 16. Emission graphs of D50E40B10 blend running at 1600 RPM at different intake temperature.

However, the hydrocarbon emissions decreased with the increased intake temperature, because the increased temperature has a good tendency to burn all the fuels that contain high ethanol contents due to the high auto-ignition temperature of hydrogen and long ignition delay. From the combustion characteristics and emission analysis, $T_{i}=350 \mathrm{~K}$ is the most suitable intake temperature to ignite the D50E40B10 blends with low emission and low effect of abnormal combustion.

\subsection{Effect of Modification on Combustion Characteristics and Emissions}

Here, we compare all the injection modifications, compression ratios, and intake temperatures in order to determine the best combustion efficiency and emissions. Figure 17 shows the pressure and HRR graph of the D50E40B10 blends running at 1600 RPM. The results show that the compression 
ratio modification has a dominant effect on in-cylinder pressure and HRR. Besides, injection timing modification also gives a very small effect on the combustion, since the ignition of the blend at this condition is very weak. However, the heat rate released from the combustion for ambient temperature modification and compression ratio modification shows no significant difference except the ignition delay. Operating the D50E40B10 blend at an ambient temperature of $350 \mathrm{~K}$ has a shorter ignition delay than that operated at a compression ratio of 20 .

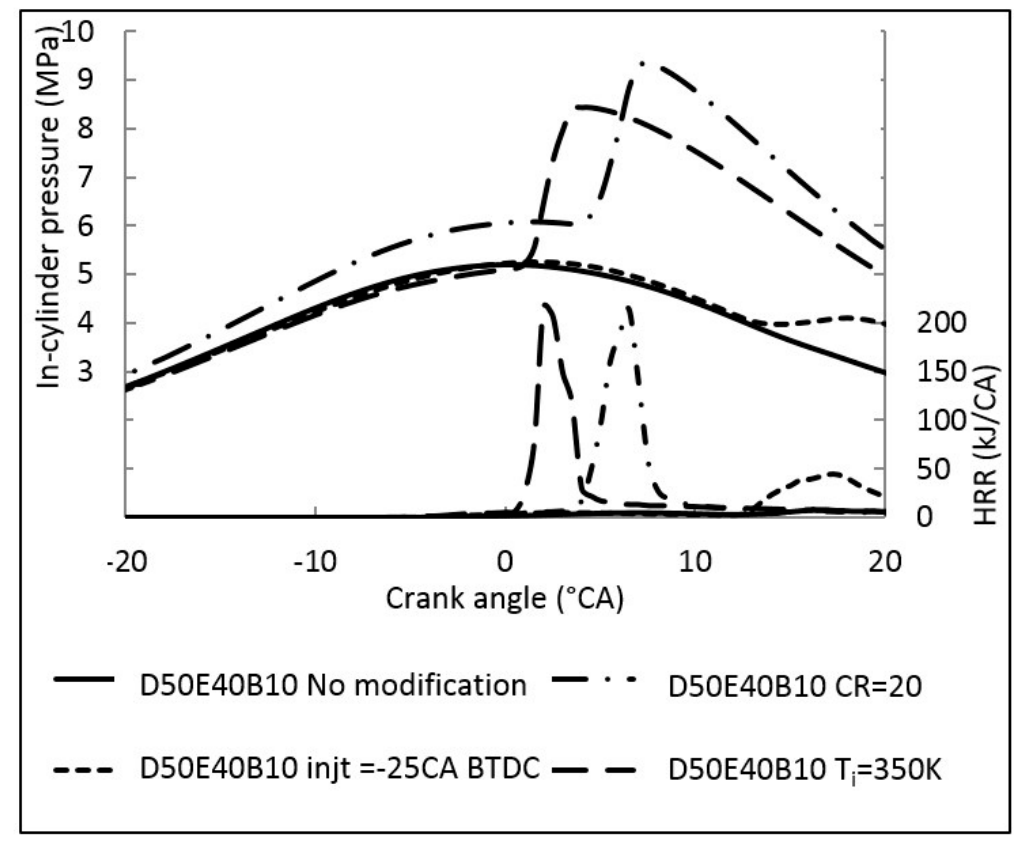

Figure 17. Pressure and HRR graphs of the D50E40B10 blend running at 1600 RPM at different modification comparisons.

Figure 18 shows the comparison of emissions between the injection timing advancement, compression ratio, and intake temperature modification. Although the modification of engine intake temperature and compression ratio release has high HRR and pressure, the emission of this modification is severed compared with the other modifications. The graphs show that increasing the engine intake temperature increases the $\mathrm{CO}$ and $\mathrm{NO}_{x}$ emissions. The reason is that the high temperature from the combustion and high oxygen contents from the blends leads to the $\mathrm{NO}_{x}$ formation. Therefore, intake temperature modification was chosen as the best engine modification to solve the blend ignition problem, improve the combustion efficiency, shorten the ignition delay, and reduce the carbon emissions. 

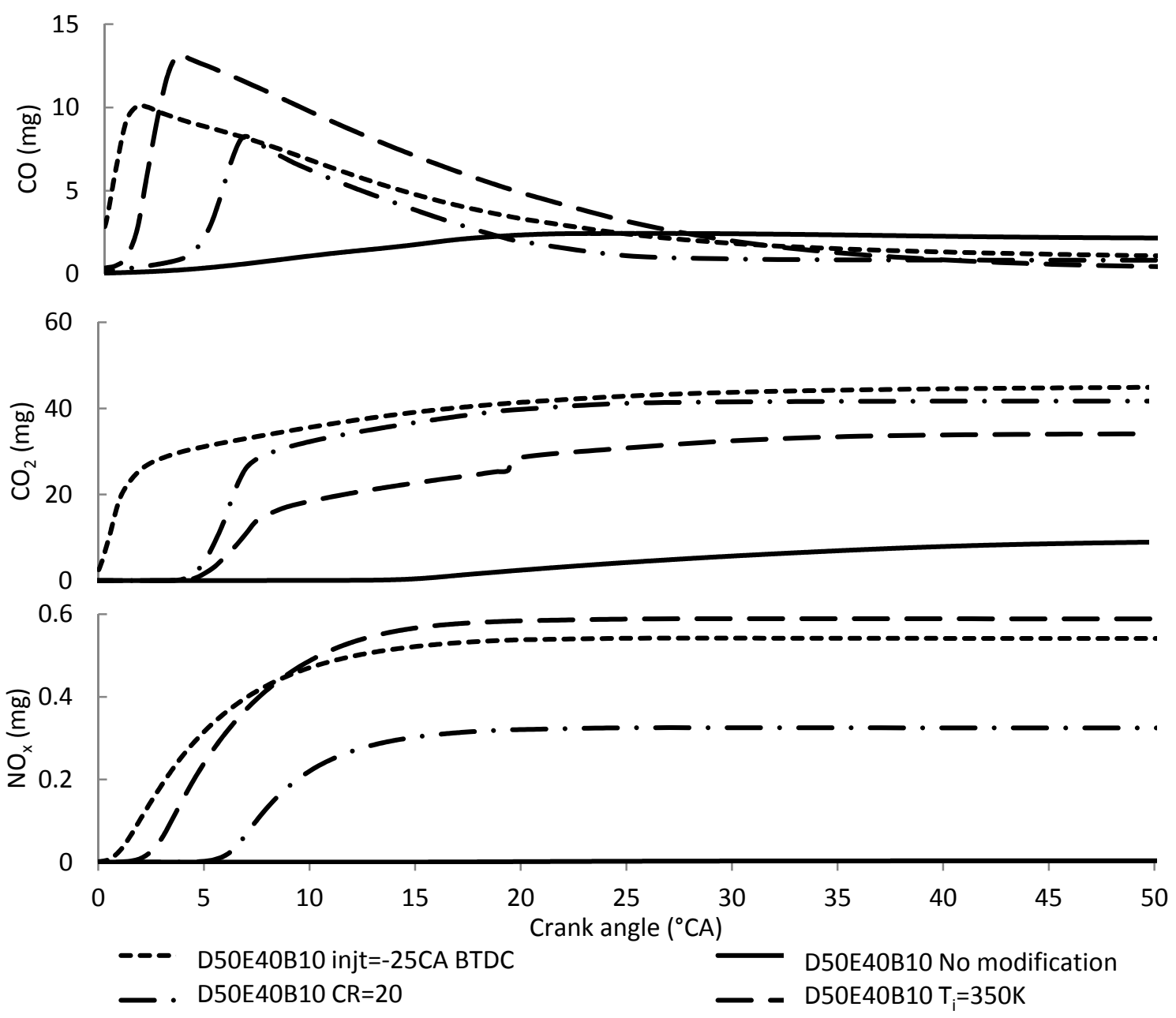

Figure 18. Comparison of $\mathrm{CO}, \mathrm{CO}_{2}$, and $\mathrm{NO}_{x}$ emissions of $\mathrm{D} 50 \mathrm{E} 40 \mathrm{~B} 10$ blends at the best injection modification, compression ratio, and intake temperature.

\section{Conclusions}

Blending diesel, ethanol, and PME in a diesel engine with different compositions results in a different ignitability behavior. Ethanol with a low heating value and low cetane number reduces the ignition ability due to the long ignition delay. A simulation study has been conducted for different diesel-ethanol-PME compositions. From the simulation, the following conclusions are drawn:

1. High ethanol contents reduce the ignitability of the blends, and the maximum speed achieved by D50E25B25 only at 1600 RPM and D50E40B10 was not ignited at both engine speeds.

2. Changing the injection duration and increasing the injected mass was not helpful enough to ignite the D50E40B10 blends at 1600 RPM and 2400 RPM. Meanwhile, advancing the injection timing at approximately $-25{ }^{\circ} \mathrm{CA}$ increased the in-cylinder pressure and its HRR. Advancing the injection timing successfully ignites the fuel blends. However, the combustion was so weak, and the ignition delay was too long. Moreover, advancing the injection earlier than $-25^{\circ} \mathrm{CA}$ increases the $\mathrm{NO}_{x}$ emission.

3. Therefore, modification of the compression ratio and ambient temperature produces good results in improving the ignitability of D50E40B10 blends with minimum CR20 at 1600 RPM and CR24 at 2400 RPM. Increasing the ambient temperature by implementing an air-heating or EGR system to the engine can improve the ignitability. The most suitable intake temperature for the D50E40B10 blend is $350 \mathrm{~K}$, producing high peak pressure and HRR. 
4. From the comparison between all the modifications of injection, compression ratio, and intake temperature, the most suitable modification for diesel-ethanol-PME blends is increasing the intake temperature. This procedure produces increased in-cylinder pressure and HRR, but has a short ignition delay. Although the $\mathrm{NO}_{x}$ emission of intake temperature modification is slightly high, the abnormal combustion phenomena can be avoided compared with the compression ratio modification.

In the future, the heating system should be mounted to the intake to increase the air intake temperature in the real engine application. Further studies on the diesel-ethanol-PME blend ignitability on the engine performance, combustion characteristics, and emissions should be investigated and another approach to reduce the emission focusing on $\mathrm{NO}_{x}$ emission should be applied.

Author Contributions: Conceptualization and Methodology N.M.T and M.R.A.M; Software, Validation, Analysis and Writing-Original Draft Preparation N.M.T; Writing-Review and Editing M.R.A.M; Supervision M.R.A.M and W.M.F.W.M.

Funding: This research was funded by Universiti Kebangsaan Malaysia [Grant number: GUP-2018-099].

Acknowledgments: The authors thank the Ministry of Higher Education Malaysia and Universiti Kebangsaan Malaysia for supporting and funding this research.

Conflicts of Interest: The authors declare no conflict of interest.

\section{References}

1. Monirula, I.M.; Masjukia, H.H.; Kalama, M.A.; Mosarofa, M.H.; Zulkiflia, N.W.M.; Teohab, Y.H.; How, H.G. Assessment of performance, emission and combustion characteristics of palm, jatropha and calophyllum inophyllum biodiesel blends. Fuel 2016, 181, 985-995. [CrossRef]

2. Ganjehkaviri, A.; Jaafar, M.N.M.; Hosseini, S.E.; Musthafa, A.B. Performance evaluation of palm oil-based biodiesel combustion in an oil burner. Energies 2016, 9, 97. [CrossRef]

3. Taib, N.M.; Mansor, M.R.A.; Mahmood, W.M.F.W.; Abdullah, N.R. Simulation Study of Combustion Characteristics of Diesel- Ethanol-Palm Oil Methyl Ester Blends in Diesel Engine. J. Adv. Res. Fluid Mech. Therm. Sci. 2018, 44, 149-156.

4. Pedrozo, V.B.; May, I.; Nora, M.D.; Cairns, A.; Zhao, H. Experimental analysis of ethanol dual-fuel combustion in a heavy-duty diesel engine: An optimisation at low load. Appl. Energy 2016, 165, 166-182. [CrossRef]

5. Yu, S.; Gao, T.; Wang, M.; Li, L.; Zheng, M. Ignition control for liquid dual-fuel combustion in compression ignition engines. Fuel 2017, 197, 583-595. [CrossRef]

6. Dong, S.; Cheng, X.; Ou, B.; Liu, T.; Wang, Z. Experimental and numerical investigations on the cyclic variability of an ethanol/diesel dual-fuel engine. Fuel 2016, 186, 665-673. [CrossRef]

7. Kumar, B.R.; Saravanan, S. Use of higher alcohol biofuels in diesel engines: A review. Renew. Sustain. Energy Rev. 2016, 60, 84-115. [CrossRef]

8. Guedes, A.D.M.; Braga, S.L.; Pradelle, F. Performance and combustion characteristics of a compression ignition engine running on diesel-biodiesel-ethanol (DBE) blends-Part 2: Optimization of injection timing. Fuel 2018, 225, 174-183. [CrossRef]

9. Sharma, A.; Murugan, S. Combustion, performance and emission characteristics of a di diesel engine fuelled with non-petroleum fuel: A study on the role of fuel injection timing. J. Energy Inst. 2015, 88, 364-375. [CrossRef]

10. Rahim, N.A.; Jaafar, M.N.M.; Sapee, S.; Elraheem, H.F. Effect on particulate and gas emissions by combusting biodiesel blend fuels made from different plant oil feedstocks in a liquid fuel burner. Energies 2016, 9, 659. [CrossRef]

11. Gnanamoorthi, V.; Devaradjane, G. Effect of compression ratio on the performance, combustion and emission of di diesel engine fueled with ethanol e Diesel blend. J. Energy Inst. 2015, 88, 19-26. [CrossRef]

12. Shahir, S.A.; Masjuki, H.H.; Kalam, M.A.; Imran, A.; Fattah, I.M.R.; Sanjid, A. Feasibility of diesel-biodiesel-ethanol/bioethanol blend as existing CI engine fuel: An assessment of properties, material compatibility, safety and combustion. Renew. Sustain. Energy Rev. 2014, 32, 379-395. [CrossRef] 
13. Kuszewski, H. Experimental investigation of the effect of ambient gas temperature on the autoignition properties of ethanol-diesel fuel blends. Fuel 2018, 214, 26-38. [CrossRef]

14. Ibrahim, F.; Mahmood, W.M.F.W.; Abdullah, S.; Mansor, M.R.A. A Review of Soot Particle Measurement in Lubricating Oil. Def. S T Tech. Bull. 2015, 8, 141-152.

15. Ibrahim, F.; Mahmoof, W.M.F.W.; Abdullah, S.; Mansor, M.R.A. Comparison of Simple and Detailed Soot Models in the Study of Soot Formation in a Compression Ignition Diesel Engine. SAE Int. 2017. [CrossRef]

16. Pradelle, F.; Braga, S.L.; Fonseca de Aguiar Martins, A.R.; Turkovics, F.; Nohra Chaar Pradelle, R. Performance and combustion characteristics of a compression ignition engine running on diesel-biodiesel-ethanol (DBE) blends-Potential as diesel fuel substitute on an Euro III engine. Renew. Energy 2019, 136, 586-598. [CrossRef]

17. Adnan, R.; Masjuki, H.H.; Mahlia, T.M.I. Performance and emission analysis of hydrogen fueled compression ignition engine with variable water injection timing. Energy 2012, 43, 416-426. [CrossRef]

18. Raeie, N.; Emami, S.; Sadaghiyani, O.K. Effects of injection timing, before and after top dead center on the propulsion and power in a diesel engine. Propuls. Power Res. 2014, 3, 59-67. [CrossRef]

19. Labeckas, G.; Slavinskas, S.; Mažeika, M. The effect of ethanol-diesel-biodiesel blends on combustion, performance and emissions of a direct injection diesel engine. Energy Convers. Manag. 2014, 79, 698-720. [CrossRef]

20. Hariram, V.; Shangar, R.V. Influence of compression ratio on combustion and performance characteristics of direct injection compression ignition engine. Alex. Eng. J. 2015, 54, 807-814. [CrossRef]

21. Muralidharan, K.; Vasudevan, D. Performance, emission and combustion characteristics of a variable compression ratio engine using methyl esters of waste cooking oil and diesel blends. Appl. Energy 2011, 88, 3959-3968. [CrossRef]

22. Hoseini, S.S.; Najafi, G.; Ghobadian, B.; Mamat, R.; CheSidik, N.A.; Azmi, W.H. The effect of combustion management on diesel engine emissions fueled with biodiesel-diesel blends. Renew. Sustain. Energy Rev. 2017, 73, 307-331. [CrossRef]

23. Bora, B.J.; Saha, U.K.; Chatterjee, S.; Veer, V. Effect of compression ratio on performance, combustion and emission characteristics of a dual fuel diesel engine run on raw biogas. Energy Convers. Manag. 2014, 87, 1000-1009. [CrossRef]

24. Amarnath, H.K.; Prabhakaran, P.; Bhat, S.A.; Paatil, R. A comparative analysis of thermal performance and emission characteristics of methyl esters of karanja and jatropha oils based on a variable compression ratio diesel engine. Int. J. Green Energy 2014, 11, 675-694. [CrossRef]

25. Akasyah, M.K.; Mamat, R.; Abdullah, A.; Aziz, A.; Yassin, H.M. Effect of ambient temperature on diesel-engine combustion characteristics operating with alcohol fuel. Int. J. Automot. Mech. Eng. 2015, 11, 2373-2382. [CrossRef]

26. Linkenhoger, T. Intake Air Pre-Heated Assembly for Automotive Gasoline Engines. U.S. Patent 20050257781 A1, 24 November 2005.

27. Pan, W.; Yao, C.; Han, G.; Wei, H.; Wang, Q. The impact of intake air temperature on performance and exhaust emissions of a diesel methanol dual fuel engine. Fuel 2015, 162, 101-110. [CrossRef]

(C) 2019 by the authors. Licensee MDPI, Basel, Switzerland. This article is an open access article distributed under the terms and conditions of the Creative Commons Attribution (CC BY) license (http://creativecommons.org/licenses/by/4.0/). 